\title{
Experimental models for studying mucociliary clearance
}

\author{
M. King
}

Experimental models for studying mucociliary clearance. M. King. (CERS Journals Ltd 1998.

ABSTRACT: Respiratory tract mucus is a viscoelastic gel, the rheological properties of which are determined mainly by its content of mucous glycoproteins and water. The rheology and quantity of mucus, in concert with ciliary factors, are the major determinants of mucociliary clearance.

A wide range of animal models for studying the secretion and clearance of mucus are available. $E x$ vivo models, such as the frog palate or excised bovine trachea, provide direct, meaningful data regarding the clearability of mucus. Rodent models of chronic bronchitis, based on irritant gas or cigarette smoke exposure, show important features of the human condition in a relatively short time. The rheological characterization of mucus is made difficult by the small quantities obtainable, particularly from normal animals.

Large animal models, such as the dog or sheep, although more expensive, offer many advantages, such as the ability to carry out long-term serial measurements, and to make integrated measurements of the clearance of mucus, ciliary function, epithelial ion transport, and the rheology of mucus in the same preparation. Eur Respir J 1998; 11: 222-228.
Pulmonary Research Group, University of Alberta, Edmonton, AB T6G 2S2, Canada.

Correspondence: M. King

Pulmonary Research Group

University of Alberta

Edmonton

AB T6G 2S2

Canada

Fax: 0014034924878

Keywords: Chronic bronchitis mucociliary clearance mucous rheology

Received: February 241997 Accepted for publication April 161997

\section{The viscoelastic properties of mucus}

Due to the cross-linking of glycoproteins, the rheological behaviour of mucus is described as viscoelastic, having characteristics of both a liquid and a solid [1, 2]. Viscosity is the resistance to flow, and represents the capacity of a material to absorb energy as it moves. Elasticity is the capacity of a material to store the energy used to move or deform it. With ideal fluids, viscosity is independent of the stress applied. With viscoelastic liquids, such as mucus, viscosity decreases with increasing stress or rate of strain (shear rate). Mucus responds to stress with an initial solid-like deformation, followed by a viscoelastic deformation and finally by a period of steady flow, in which the rate of deformation is constant. Only partial recovery of the strain follows removal of the stress, indicating a permanent deformation of its gel structure. Changes in the viscosity and elasticity of mucus are generally interrelated.

Mucus exhibits shear-thinning following exposure to high shear forces, exhibiting a decreased viscosity at low shear rates. Some shear-thinning may be permanent, indicating altered molecular structure, whilst some shearthinning, termed "thixotropy", may be reversible.

The viscoelasticity of mucus can be effectively described by two relatively independent quantities, $\mathrm{G}^{*}$ and tangent $(\tan ) \delta$, which vary with measurement frequency. The mechanical impedance $\left(G^{*}\right)$, is the vector sum of viscosity and elasticity; it can be termed the "rigidity factor". Tan $\delta$ is the ratio of viscosity to elasticity; it is also known as the loss tangent and can be considered as a "recoil factor". The relative proportions of elasticity and viscosity are important in describing how a material, such as mucus, behaves when it is subjected to external forces.

\section{Rheological assessment of mucus}

\section{Collection of mucus}

Tracheal mucus can be collected by a modification of the cytology brush technique or the endotracheal tube collection technique [2]. Cytology brush collection involves placing a soft-bristled cytology brush against the pulmonary airway and removing the brush once it is covered with sufficient mucus for analysis. Endotracheal tube collection involves the removal of the mucous layer coating a freshly removed endotracheal tube. These techniques provide sufficient mucus for analysis even from very small animals [3].

\section{Magnetic microrheometer}

This instrument can be used to measure the bulk viscosity and elasticity of microlitre quantities of mucus

Previous articles in this series: No. 1: P.K. Jeffery, D. Li. Airway mucosa: secretory cells, mucus and mucin genes. Eur Respir $J$ 1997; 10: 1655-1662. No. 2: W.D. Kim. Lung mucus: a clinician's view. Eur Respir J 1997; 10: 1914-1917. No. 3: L.D. Martin, L.G. Rochelle, B.M. Fischer, T.M. Krunkosky, K.B. Adler. Airway epithelium as an effector of inflammation: molecular regulation of secondary mediators. Eur Respir J 1997; 10: 2139-2146. No. 4: R. Wu, Y.H. Zhao, M.M.J. Chang. Growth and differentiation of conducting airway epithelial cells in culture. Eur Respir J 1997; 10: 2398-2403. No. 5: K.C. Kim, K. McCracken, B.C. Lee, C.Y. Shin, M.J. Jo, C.J. Lee, K.H. Ko. Airway goblet cell mucin: its structure and regulation of secretion. Eur Respir J 1997; 10: 2644-2649. No. 6: J.H. Widdicombe, S.J. Bastacky, D.X-Y. Wu, C.Y. Lee. Regulation of depth and composition of airway surface liquid. Eur Respir J 1997; 10: $2892-2897$. 
[4]. A $100 \mu \mathrm{m}$ steel ball is positioned in a $1-10 \mu \mathrm{L}$ sample of mucus and oscillated by means of an electromagnetic field gradient. The motion of this sphere is tracked with the aid of a photocell. Plots of ball displacement versus magnetic force are used to determine the viscosity and elasticity of the mucus as a function of applied frequency. These rheological properties can be used to predict the effectiveness of mucus in clearance, both by ciliary action and by airflow interaction [5]. The magnetic microrheometer is particularly suited to studies employing animal models because of the minimal sample requirement.

\section{Filancemeter}

Spinnability (also known as Spinnbarkeit or filance) is the thread-forming ability of mucus under the influence of low speed elastic deformation. Using a filancemeter [6], a [20-30 $\mu \mathrm{L}]$ sample of mucus is stretched at a retraction velocity of $10 \mathrm{~mm} \cdot \mathrm{s}^{-1}$. An electric signal conducted through the sample of mucus is interrupted at the point where the mucous thread is broken; the length of this thread is known as the mucous spinnability (in $\mathrm{mm})$. Spinnability has been correlated positively with mucociliary clearance [6], and negatively with cough clearance [7]. Although the filancemeter requires greater volumes of mucus than the magnetic microrheometer, it has two main advantages: its ease of use; and the fact that the measurements appear to be more sensitive to alterations in molecular weight of cross-linking macromolecules, as evidenced by the response of cystic fibrosis sputum to deoxyribonuclease (DNase) and gelsolin [8].

Adhesivity is the ability of mucus to bond to a solid surface, measured as the force of separation between one or more solid surfaces and the adhesive material. This is dependent on mucus surface tension, hydration, wettability, and contact (dwell) time. Adhesivity has been found to correlate inversely both with mucociliary clearance and cough clearance $[7,9]$.

\section{Solids content/collection rate}

There is generally a positive relationship between the solid composition of mucus and the viscoelastic properties, although the relationship can change with disease state or source of mucus [10]. We use a microwave drying apparatus and microbalance to calculate the percentage solids for samples of mucus larger than $5 \mu \mathrm{L}$. The samples of mucus are also weighed to determine an index of secretion rate (collection rate of mucus in $\left.\mathrm{mg} \cdot \mathrm{min}^{-1}\right)$. In dogs, knowing the linear velocity of mucus, the airway circumference and the collection rate, the in vivo depth of mucus can be estimated [11].

\section{Transepithelial potential difference}

The transepithelial potential difference (PD) represents an integral of the ion fluxes across an epithelial membrane. PD measurements are useful in mucociliary clearance studies, since variations in PD relate to chan- ges in the ion and water content of mucus [12]. They also help to assess the integrity of the epithelium, since alterations of cellular and paracellular pathways contribute to PD. PD is measured by using two flexible microelectrodes connected with $\mathrm{KCl}$-saturated agar bridges to calomel half-cells. The reference electrode is placed subcutaneously, and the test electrode is placed at various locations on the epithelial surface. Our laboratory has made extensive use of this technique in rats, dogs and frogs [13-15].

\section{Mucus and mucociliary clearance}

There are two major mechanisms for clearing mucus from the airways: by ciliary action, the primary mechanism; and when this fails or is overloaded, by coughing or other forms of airflow interaction. Methods for studying mucociliary clearance range from in vitro direct observation (e.g. frog palate) to in vivo tracer methods (e.g. inhaled, radiolabelled particles). Cough or airflow clearance can be studied in mechanical models, as well as in vivo, with the use of appropriate tracers.

In dogs and other large animals, tracheal mucus velocity (TMV, $\left.\mathrm{mm} \cdot \mathrm{min}^{-1}\right)$, i.e. the "linear" velocity of mucociliary clearance, can be determined by direct observation of marker particle movement with the aid of a fibreoptic bronchoscope [16]. Mainstem bronchial mucus velocities can also be measured under bronchoscopic control; these are useful in monitoring the effects of local or unilateral interventions. The main advantages of measuring TMV is that it is straightforward, and that it can be carried out at the same anatomical site where measurements of epithelial PD are performed, and from where mucus is collected for rheological and chemical analysis.

The viscoelasticity of the mucous layer contributes to the effectiveness of the mucociliary interaction, but the surface interaction between mucus and cilia also play a critical role. The transport velocity of mucous simulant gels is directly related to the elasticity of mucus and the depth of the periciliary fluid, and is inversely related to the viscosity of mucus [5]. GIORDANo et al. [17] studied the TMV of dogs prepared with tracheal pouches, and found a clear negative correlation between the in vivo tracheal clearance rate and the elasticity of the mucus secreted by the pouch. Results, generally similar to this, have been obtained in studies employing the frog palate as a model of ciliated epithelium, i.e. ciliary transport rate decreases with increasing rigidity or "thickness" of the mucus, whatever quantitative measure is used $[1,18,19]$. A similar relationship between the viscoelasticity and clearance of mucus has also been demonstrated for rat nasal epithelium [20].

The ratio of viscosity to elasticity is also an important determinant of mucociliary clearance. Increasing viscosity at constant elasticity in a model system caused a pronounced decrease in the mucociliary transport rate [19]. Although this phenomenon has not been observed for intact mucus from healthy animals, it has been seen in pathological human material [21]. The viscosity/elasticity ratio $(\tan \delta)$ represents the ratio of mechanical energy dissipated as friction per cycle versus that stored as kinetic energy. A decrease in the velocity of 
mucus with increasing $\tan \delta$ is consistent with increased dissipation of ciliary energy by the mucus. It thus appears that decreasing either the elasticity or the viscosity/elasticity ratio of mucus would be of benefit in enhancing the clearance of secretions.

Increasing the elasticity or viscosity of mucus from normal almost invariably results in a decrease in clearance rate. However, it has been demonstrated that as the elasticity of mucus decreases from the normal range, the ciliary transport rate eventually passes through a maximum, and further decreases in the elasticity of mucus resulting in a reduction in transport rate [22]. The range of optimum mucociliary clearance of airway mucus is located at the low end of the normal range of viscoelasticity $[18,21,23]$. Overliquification of mucus by mucolytic treatments represents a potential hazard in any therapeutic trial, and consideration should be given to defining baseline rheological properties and the in vitro effect of any potential treatment before initiating its use in patients.

\section{Mucociliary versus cough clearance}

Cough clearance represents the second line of airway defence taking over, in the case of mucous overload or when mucociliary clearance becomes inadequate. The relationship between cough clearance and the rheology of mucus has been studied in vitro by means of a cough simulator [24]. The viscosity of mucus, i.e. resistance to flow, is the major rheological variable affecting cough clearance. Elasticity is involved in terms of the recoil effect, i.e. a high degree of spinnability or a low viscosity/elasticity ratio inhibits cough clearance. Adhesivity or surface tension inhibits cough clearance through the suppression of mucus/airflow interaction, which manifests itself as wave formation in the mucous layer during the cough [7]. ZAHM et al. [25] demonstrated that mucous thixotropy and shear-thinning were important in describing the movement of mucus in multiple rapid coughs, and, by extension, high frequency oscillation.

Both forms of mucous clearability (by cough and by ciliary action) can be successfully predicted on the basis of the measurement of the viscoelastic properties of mucus. Mucus that is elastic rather than viscous is transported well by ciliary action, but less well by coughing [5]. The existence of an optimal range of viscoelastic properties, and the fact that in some cases both mucociliary and cough clearance should be optimized, suggests that therapeutic measures designed to modify the rheology of secretions should consider the initial state of the mucus, and that the monitoring of the viscoelastic properties of the mucus should be an essential part of any potential mucotropic therapy.

\section{$E x$ vivo ciliary transportability}

The frog palate can be used to assay mucociliary clearability. The epithelium of frog palate is ciliated and mucus-secreting, similar to that found in human conductive airways. Leopard frogs (Rana pipiens) or bullfrogs (Rana catesbiana) are prepared by double pithing, i.e. bending the head forward and inserting an 18-gauge needle into the brain and the spinal cord. The jaw is disarticulated and the palate removed by cutting through from the junction of the posterior pharynx and oesoph- agus out to the skin of the back. The excised palate is placed on gauze saturated with "amphibian" Ringer's solution (2/3 mammalian Ringer's solution and 1/3 distilled water; $\left.207 \mathrm{mOsm} \cdot \mathrm{L}^{-1}\right)$. The preparation is loosely covered with plastic wrap and allowed to rest in a refrigerator at $4-6^{\circ} \mathrm{C}$ for $12-24 \mathrm{~h}$ to allow depletion of mucus. The palate is then rewarmed to room temperature and placed in an acrylic chamber, where humidity is maintained by Ringer's aerosol. The palate is focused under a dissecting microscope fitted with a micrometer scale, and the movement of a $2-5 \mu \mathrm{L}$ aliquot of mucus is timed; 3-5 measurements of the transport rate of mucus are taken to minimize measurement variability. The average transport rate of a sample is normalized to the transport rate for collected endogenous frog mucus [26, 27]. This technique has been widely used as a means of defining the inherent "transportability" of mucus, independent of systemic ciliary function.

WiLls et al. [28] have recently developed a mammalian alternative to the frog palate assay, using excised bovine trachea depleted of endogenous mucus by repeated passage of mucus. Although the bovine preparation appears to be more cumbersome than the traditional frog palate, which requires no active treatment to effect depletion of mucus, WILLs et al. [29] have used this preparation to advantage in monitoring the effects of in vitro treatment of sputum with salt as a potential "mucolytic" therapy.

Although the frog palate assay requires only microlitre volumes of mucus, this test should be interpreted with caution in experiments where residual mediators in the mucus could cause alterations in the frog palate ciliary activity and invalidate the basic assumption that ciliary activity is normalized [30]. In fact, by observing the clearance of collected frog mucus or a standard preparation of mucus, one can monitor the effects of cilioactive drugs delivered to the frog palate, since variations in clearance rate can, in this case, be attributed to changes in ciliary activity.

When used in a fresh condition, before depletion of the endogenous mucous layer (within $3 \mathrm{~h}$ of excision at room temperature), the frog palate provides an excellent integrated model system for studying all of the relevant variables for mucociliary clearance, namely the secretion rate of mucus, the rheology of mucus, the ciliary beat frequency, the transepithelial PD, and the linear velocity of mucus. We have used the freshly-excised frog palate model in several recent studies, involving alteration of epithelial ion and water transport with amiloride and uridine triphosphate (UTP) $[15,31]$, and the effects of artificial pulmonary surfactant [32]. Freshly excised mammalian tracheas can also be used as integrated model systems for mucociliary transport. GERBER et al. [33] have recently carried out such a study with horse trachea, where concurrent measurements of particle transport, ciliary beat frequency, and grading of mucus were made. Even in animals as small as mice, it is possible to carry out integrated studies of mucociliary function [34].

\section{Animal models for hypersecretion}

Chronic bronchitis is primarily an airway disease, involving mucous glands and goblet cell hypertrophy, 
leading to inflammation and infection, which further amplifies the elevated production of mucus $[35,36]$. Alterations in the chemical nature of the mucous glycoproteins [37] and impaired mucociliary clearance [38] are important hallmarks of the disease. Chronic bronchitis is not necessarily associated with smooth muscle or parenchymal dysfunction, although clearly these often co-exist with the airway disease. The principal aetiological factor in the development of chronic bronchitis is cigarette smoking, whilst atmospheric air pollution and environmental tobacco smoke also play important roles in the development of this condition.

In an animal model, we are primarily looking for enhancement of the airway production of mucus, combined with slowed mucociliary clearance leading to retention of secretions. Such a model would be useful in designing and testing new therapy for clearance disorders of mucus.

\section{Small animal models of chronic bronchitis}

Considerable work has been performed using the rat as a model for chronic bronchitis. The major approaches have been to use either exposure to $\mathrm{SO}_{2}$ gas [39, 40], or to air-diluted cigarette smoke [41, 42]. With either agent, 1-3 weeks exposure is generally sufficient to produce pathological changes related to human bronchitis. These include an increase in goblet cell numbers as well as in the size of submucosal glands. Proliferation of goblet cells to more peripheral airways and a histochemical shift towards acid mucin are also seen. In our experience with cigarette smoke exposed rats (fig. 1), the quantity of tracheal mucus increases markedly with 13 weeks exposure, and the viscoelasticity of mucus is altered in the direction of less rigidity [43]. Tobacco smoke models are particularly relevant to human chronic bronchitis, since the main aetiological factor is the

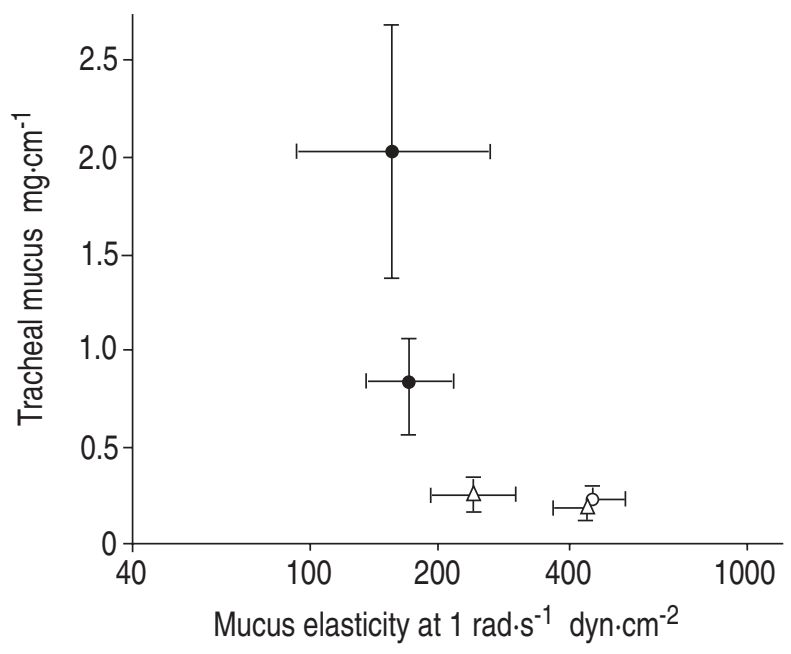

Fig. 1. - The influence of tobacco smoke on the quantity and physical quality of tracheal mucus in Sprague-Dawley rats. Rats were exposed to cigarette smoke diluted $30: 1$ by air daily for 1-3 weeks Mucus was obtained by sacrificing the rats 3-4 days after the last exposure and scraping the exposed trachea with a scalpel blade. The elasticity of the mucus was determined by magnetic rheometry [4], after which the samples were weighed. Values are presented as mean \pm SEM. Each point represents the data from six rats. $\bullet: 48$ cigarettes $^{-}$day $^{-1}$,

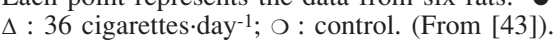

same; however, such experiments have become increasingly difficult to carry out because of ethical and social considerations.

In more recent years, a variety of models for chronic bronchitis have been developed. Endotoxin exposure has been used successfully to induces chronic bronchitis type changes in rats with as little as 3 days of exposure [44]. This model showed the appearance of mucus-containing cells in peripheral airways 3-10 days following the last instillation of the endotoxin. Although the lesion develops perhaps too rapidly, the exposure may be biologically relevant in lower doses, particularly as it relates to endotoxin exposure in agricultural workers.

Urban air pollution in a heavily industrialized city (São Paulo, Brazil) has been used to produce experimental bronchitis in rats $[45,46]$. In this case, the lesion develops much more slowly, in 3-6 months, but otherwise shares many of the features expected for a successful model for bronchitis. The value of this model is its biological and social relevance to a real problem affecting many of the largest cities. The disadvantages are the length of time required to develop the lesion, and the variability of the environmental insult over time and location.

Recently, sodium metabisulphite (MBS), which releases sulphur dioxide in situ, has been used to produce similar lesions to the classic $\mathrm{SO}_{2}$-induced bronchitis. PoN et al. [47] have found that 3 weeks of exposure to MBS aerosol in rats causes an increase in epithelial goblet cell number, and a shift to a more acidic mucin. Because of the lower risk to laboratory personnel, this model may provide a suitable alternative to $\mathrm{SO}_{2}$ gas or tobacco smoke.

A wide variety of agents applied in vitro or in culture systems have been shown to produce hypersecretion of mucus or upregulation of the production of mucus. These include cholinergic agonists, histamine, neuropeptides, adenosine triphosphate (ATP), platelet-activating factor (PAF), tumour necrosis factor- $\alpha$ (TNF- $\alpha$ ), interleukins, elastase, and ozone. ADLER et al. [48] have recently shown that several of these agents share a common pathway to hypersecretion, namely a dependence on nitric oxide synthase.

Other small animals have also been used for studies of mucus hypersecretion. Guinea-pigs exhibit an intense response to cigarette smoke that includes both hypersecretion of mucus as well as exfoliation of tracheal cilia [49]. Ferrets show a brisk tracheal response to methacholine and substance $\mathrm{P}$ as secretagogues [50], but an even more intense response to neutrophil elastase [51].

\section{Large animal models for mucus hypersecretion}

Perhaps the most useful large animal model of mucus hypersecretion has been the dog. Lengthy periods of cigarette smoke exposure in the dog, up to $1 \mathrm{yr}$, produce well-developed airway changes consistent with the pattern of chronic bronchitis: goblet cell hyperplasia and metaplasia, increased mass of submucosal glands, and a more acidic mucin $[52,53]$. Long-term smoke exposure also results in significant slowing of tracheal mucociliary clearance [54]. Our own studies on dogs exposed to whole cigarette smoke through a tracheostomy (fig. 2) showed that hypersecretion developed in most dogs 


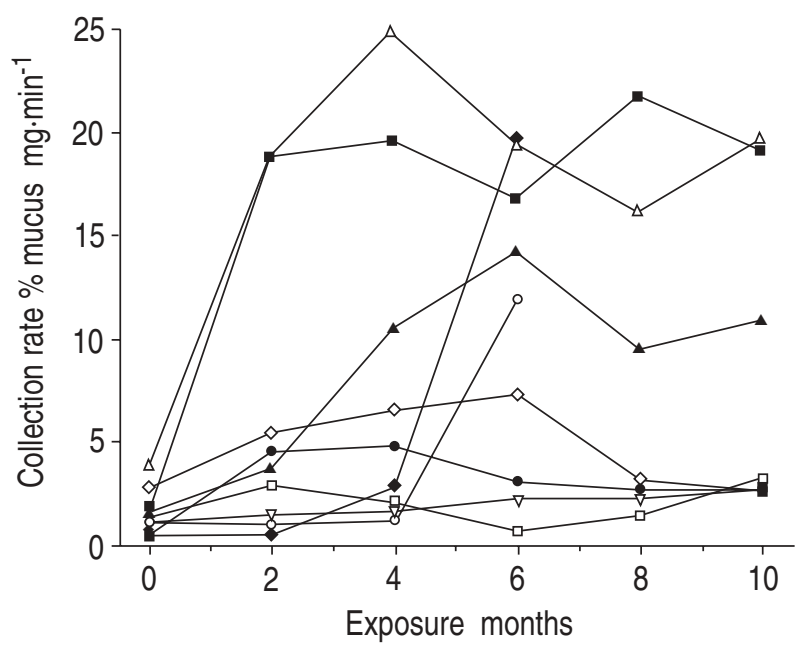

Fig. 2. - Collection rates of tracheal mucus in nine beagle dogs before and after exposure to cigarette smoke for periods of 6-10 months. The dogs were exposed for 5 days.week ${ }^{-1}$ to whole smoke from 10 cigarettes $\cdot$ day $^{-1}$ delivered via a tracheostomy tube. The mucus was collected on a cytology brush inserted through the tracheostomy and placed in contact with the posterior tracheal membrane. Each data point represents the mean of up to 16 values determined over a 2 month interval. Each dog is represented by a different symbol. (From [55]).

within 2-4 months of exposure [55]. The initial hypersecretion was associated with decreased viscosity and elasticity, which gradually recovered towards normal during 6-10 months of continued exposure. However, the mucin appeared to change character, assaying for considerably less neutral mucin than early in the exposure period.

$\mathrm{SO}_{2}$ exposure in dogs (50-200 parts per million (ppm) by tracheostomy for 3-6 months, or up to $650 \mathrm{ppm}$ by nose and mouth) appears to produce similar histological changes to the airway epithelium as those due to cigarette smoke, i.e. epithelial thickening and an increase in the size of mucous glands $[56,57]$, and the expression of mucous glycoprotein typical of chronic bronchitis in humans [58]. Our findings on the rheology and clearability of mucus with $\mathrm{SO}_{2}$ exposure in dogs (fig. 3 ) showed similarities with the response to cigarette smoke, namely an increased quantity of less rigid, more easily clearable mucus [59]. The upregulation of the production of mucus and hypersecretion of watery, more easily clearable mucus appears to be a natural and common response to airway injury involving loss or damage to the cilia.

The animal model findings have their parallels in human chronic bronchitis, although over a much longer time-frame of exposure. We found, for example, that respiratory mucus from asymptomatic smokers is better hydrated and more easily cleared by mucociliary action than mucus from nonsmokers [60]. However, this apparent "advantage" to smoking disappears with continued exposure, over the course of 20-40 pack-years, and abnormalities in the elastic recoil of mucus predictive of poor cough clearance eventually develop [61]. The decrease in lung clearance due to cigarette smoking has been well-correlated with pack-years of exposure [62].

Acute exposures in dogs have been used in a variety of situations to produce hypersecretion. Some examples

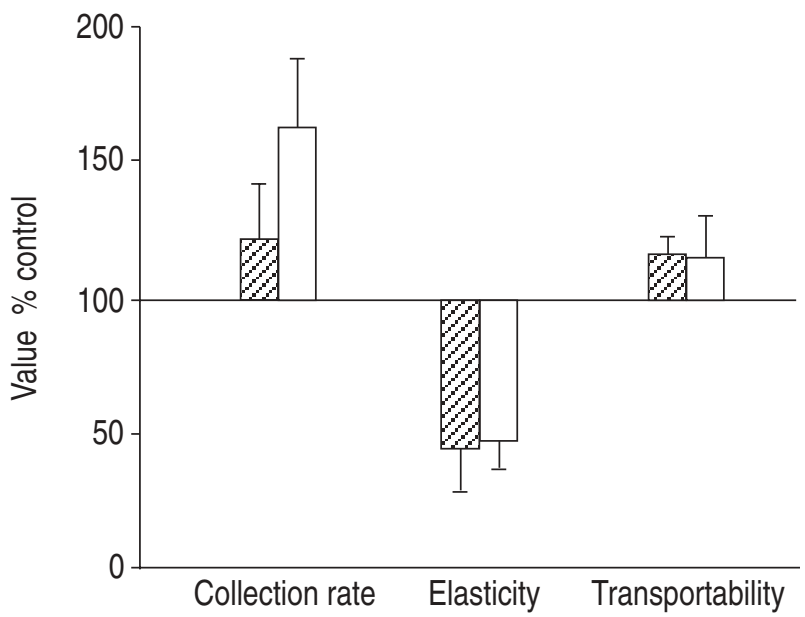

Fig. 3. - Quantity, elasticity and ciliary transportability of tracheal mucus in seven beagle dogs exposed to sulphur dioxide $\left(\mathrm{SO}_{2}\right)$ gas via nose and mouth. The dogs were exposed for $2 \mathrm{~h} \cdot \mathrm{day}^{-1}, 3$ days. week ${ }^{-1}$ for $10-13$ months. The concentration of $\mathrm{SO}_{2}$ was increased from 350 to $650 \mathrm{ppm}$ over the exposure period. Tracheal mucus was collected on a cytology brush passed through an endotracheal tube inserted under xylazine analgesia. The elasticity of the mucus was determined by magnetic rheometry, and ciliary transportability by means of the frog palate technique [26]. The results illustrated compare the chronic effect, 3 days after the last exposure versus the acute effect, immediately after $2 \mathrm{~h}$ exposure to $\mathrm{SO}_{2}$ gas during the first month of the study. Values are presented as mean \pm SEM. $\square$ : acute exposure; $\square$ : chronic exposure, i.e. 10-13 months. (From [59]).

include methacholine, by infusion or aerosol, which induces acute hypersecretion, as well as bronchoconstriction $[11,63]$. Similarly, antigen challenge, e.g. with Ascaris suum cross-reactivity, can be employed [64]. Human neutrophil elastase (HNE) produces an acute, intense hypersecretion, accompanied by a reduced clearance rate and an elevated viscoelasticity [65], but repeated exposures would probably result in upregulation of natural inhibitors, such as secretory leucocyte protease inhibitor (SLPI), limiting the potential of this approach as a model for chronic bronchitis.

Other large animal models for mucociliary function have been used with success. Sheep sensitized to Ascaris suum antigen show prolonged impairment of mucociliary clearance, along with bronchoconstriction, and represent a useful model for altered airway clearance in asthma [66]. Mucociliary clearance can be studied in a variety of large animal species, including primates, cows and horses. Intraspecies differences in the rheology and clearance of mucus have recently been reviewed by TomkiEwicz et al. [67]. The choice of species ultimately depends on which features of human chronic bronchitis one desires to emulate.

\section{References}

1. King M. Mucus, mucociliary clearance and coughing. In: Bates DV, ed. Respiratory Function in Disease. 3rd Edn. Philadelphia, Saunders, 1989; pp. 69-78.

2. King M, Rubin BK. Rheology of airway mucus: relationship with clearance function. In: Takishima T, Shimura S, eds. Airway Secretion: Physiological Bases for the Control of Mucous Hypersecretion. New York, Marcel Dekker, 1994; pp. 283-314. 
3. App EM, King M. Tracheal mucus rheology and potential difference in two day old puppies. Biorheology 1990; 27: 515-526.

4. King M. Magnetic microrheometer. In: Braga PC, Allegra L, eds. Methods in Bronchial Mucology. New York, Raven Press, 1988; pp. 73-83.

5. King M. Role of mucus viscoelasticity in cough clearance. Biorheology 1987; 24: 589-597.

6. Puchelle E, Zahm JM, Duvivier C. Spinnability of bronchial mucus: relationship with viscoelasticity and mucus transport properties. Biorheology 1983; 20: 239-249.

7. King M, Zahm JM, Pierrot D, Vaquez-Girod S, Puchelle E. The role of mucus gel viscosity, spinnability, and adhesive properties in clearance by simulated cough. Biorheology 1989; 26: 737-745.

8. Dasgupta B, Tomkiewicz RP, De Sanctis GT, Boyd WA, King M. Rheological properties in cystic fibrosis airway secretions with combined rhDNase and gelsolin treatment. In: Singh M, Saxena VP, eds. Advances in Physiological Fluid Dynamics. New Delhi, Narosa, 1996; pp. 74-78.

9. Puchelle E, Zahm JM, Jacquot J, Plotkowski C, Duvivier C. A simple technique for measuring adhesion tension properties of human bronchial secretions. Eur J Respir Dis 1987; 71 (Suppl. 153): 281-282.

10. Tomkiewicz RP, App EM, Zayas JG, et al. Amiloride inhalation therapy in cystic fibrosis: influence on ion content, hydration and rheology of sputum. Am Rev Respir Dis 1993; 148: 1002-1007.

11. King M, Kelly S, Cosio M. Alteration of airway reactivity by mucus. Respir Physiol 1985; 62: 47-59.

12. Tomkiewicz RP, App EM, De Sanctis GT, et al. A comparison of a new mucolytic $\mathrm{N}$-acetylcysteine L-lysinate with $\mathrm{N}$-acetylcysteine: airway epithelial function and mucus changes in dog. Pulm Pharmacol 1995; 8: 259-265.

13. De Sanctis GT, App EM, Trask JK, et al. Resorptive clearance and transepithelial potential difference in capsaicin-treated F344 rats. J Appl Physiol 1990; 68: 18261832.

14. App EM, Zayas JG, King M. Rheology of mucus and epithelial potential difference: small airways $v s$ trachea. Eur Respir J 1993; 6: 67-75.

15. Festa E, Macchione M, Paiva PSO, Lorenzi G, Saldiva PHN, King M. Effects of aerosolized amiloride on mucociliary transport velocity and transepithelial potential difference in isolated frog palate. J Aerosol Med 1995; 8: $167-176$

16. King M, Phillips DM, Gross D, Vartian V, Chang HK, Zidulka A. Enhanced mucus clearance with high frequency chest wall compression. Am Rev Respir Dis 1983; 128: 511-515.

17. Giordano AM, Holsclaw D, Litt M. Mucus rheology and mucociliary clearance: Normal physiological state. $\mathrm{Am}$ Rev Respir Dis 1978; 118: 245-254.

18. King M. Interrelation between mechanical properties of mucus and mucociliary transport: effect of pharmacologic interventions. Biorheology 1979; 16: 57-68.

19. King M. Relationship between mucus viscoelasticity and ciliary transport in guaran gel/frog palate model system. Biorheology 1980; 17: 249-254.

20. Lorenzi G, Böhm GM, Guimarães ET, Costa Vaz MA, King M, Saldiva PHN. Correlation between rheologic properties and in vitro ciliary transport of rat nasal mucus. Biorheology 1992; 29: 433-440.

21. Puchelle E, Zahm JM, Polu JM. Drug effects on viscoelasticity of mucus. Eur J Respir Dis 1980; 61: 195-208.

22. Shih CK, Litt M, Khan MA, Wolf DP. Effect of non- dialyzable solids concentration and viscoelasticity on ciliary transport of tracheal mucus. Am Rev Respir Dis 1975; 115: 989-995.

23. Dulfano MJ, Adler KB. Physical properties of sputum. VII. Rheologic properties and mucociliary transport. Am Rev Respir Dis 1975; 112: 341-347.

24. King M, Brock G, Lundell C. Clearance of mucus by simulated cough. J Appl Physiol 1985; 58: 1776-1782.

25. Zahm JM, King M, Duvivier C, Pierrot D, Girod S, Puchelle E. Role of simulated repetitive coughing in mucus clearance. Eur Respir J 1991; 4: 311-315.

26. King M, Gilboa A, Meyer FA, Silberberg A. On the transport of mucus and its rheologic simulants in ciliated systems. Am Rev Respir Dis 1974; 110: 740-745.

27. Rubin BK, Ramirez O, King M. The mucus depleted frog palate as a model for the study of mucociliary clearance. J Appl Physiol 1990; 69: 424-429.

28. Wills PJ, Garcia Suarez MJ, Rutman A, Wilson R, Cole PJ. The ciliary transportability of sputum is slow on the mucus-depleted bovine trachea. Am J Respir Crit Care Med 1995; 151: 1255-1258.

29. Wills PJ, Hall RL, Chan WM, Cole PJ. Sodium chloride increases the ciliary transportability of cystic fibrosis and bronchiectasis sputum on the mucus-depleted bovine trachea. J Clin Invest 1997; 99: 9-13.

30. King M. Measurement of mucociliary clearance using animal models. Excerpta Medica (Asia Pacific Congr Ser) 1984; 33: 2-10.

31. Festa E, Guimarães E, Macchione M, Saldiva PHN, King M. Acute effects of uridine triphosphate (UTP) on mucociliary clearance in isolated frog palate. $J$ Aerosol Med 1997; 10: 25-39.

32. Festa E, Saldiva PHN, King M. Role of Exosurf on mucociliary velocity, transepithelial potential difference and rheology in isolated frog palate. Eur Respir J 1995; 8: 297s.

33. Gerber V, Gehr P, Straub R, Frenz M, King M, Im Hof $V$. Mucus quality on horse tracheal epithelium: microscopic grading based on transparency. Respir Physiol 1997; 107: 67-74.

34. Kurosawa H, Wang CG, Dandurand RJ, King M, Eidelman DH. Mucociliary function in the mouse measured in explanted lung tissue. J Appl Physiol 1995; 79: 41-46.

35. Reid L. Mucus secretion and chronic bronchitis. Med Thorac 1967; 24: 40-43.

36. Wanner A. The role of mucus in chronic obstructive pulmonary disease. Chest 1990; 97: 11S-15S.

37. Lopata M, Barton AD, Lourenço RV. Biochemical characteristics of bronchial secretions in chronic obstructive pulmonary disease. Am Rev Respir Dis 1974; 110: 730-739.

38. Goodman RM, Yergin BM, Landa JF, Golinvaux MH, Sackner MA. Relationship of smoking history and pulmonary function tests to tracheal mucus velocity in nonsmokers, young smokers, exsmokers, and patients with chronic bronchitis. Am Rev Respir Dis 1978; 117: 205-214.

39. Reid L. An experimental study of hypersecretion of mucus in the bronchial tree. Br J Exp Pathol 1963; 44: 437-445.

40. Lamb D, Reid L. Mitotic rates, goblet cell increase and histochemical changes in mucus in rat bronchial epithelium during exposure to sulfur dioxide. J Pathol Bacteriol 1968; 96: 97-111.

41. Lamb D, Reid L. Goblet cell increase in rat bronchial epithelium after exposure to cigarette and cigar tobacco smoke. Br Med J 1969; 1: 33-35.

42. Hayaski M, Sornberger CG, Huber GL. Morphometric analyses of tracheal gland secretion and hypertrophy in 
male and female rats after experimental exposure to tobacco smoke. Am Rev Respir Dis 1979; 119: 67-73.

43. King M, Angus E. Influence of tobacco smoke on tracheal mucus in rats (Abstract). Fed Proc 1980; 39: 36.

44. Harkema JR, Hotchkiss JA. In vivo effects of endotoxin on intraepithelial mucosubstances in rat pulmonary airways: quantitative histochemistry. Am J Pathol 1992; 141: 307-317.

45. Saldiva PHN, King M, Delmonte VLC, et al. Respiratory alterations due to urban air pollution: an experimental study in rats. Environ Res 1992; 57: 19-33.

46. Lemos M, Lichtenfels AJFC, Amaro E Jr, et al. Quantitative pathology of nasal passages in rats exposed to urban levels of air pollution. Environ Res 1994; 66: 87-95.

47. Pon DJ, van Staden CJ, Boulet L, Rodger IW. Hyperplastic effects of aerosolized sodium metabisulfite on rat airway mucus-secretory epithelial cells. Can J Physiol Pharmacol 1994; 72: 1025-1030.

48. Adler KB, Fischer BM, Li H, Choe NH, Wright DT. Hypersecretion of mucin in response to inflammatory mediators by guinea-pig tracheal epithelial cells in vitro is blocked by inhibition of nitric oxide synthase. Am J Respir Cell Mol Biol 1995; 13: 526-530.

49. Hulbert WC, Walker DC, Jackson A, Hogg JC. Airway permeability to horseradish peroxidase in guinea-pigs: the repair phase after injury by cigarette smoke. Am Rev Respir Dis 1981; 123: 320-326.

50. De Sanctis GT, Rubin BK, Ramirez O, King M. Ferret tracheal mucus rheology, clearability and volume following administration of substance $\mathrm{P}$ or methacholine. Eur Respir J 1993; 6: 76-82.

51. Schuster A, Ueki I, Nadel JA. Neutrophil elastase stimulates tracheal submucosal gland secretion that is inhibited by ICI 200,355. Am J Physiol 1992; 262: L86-L91.

52. Auerbach O, Hammond ED, Kirman D, Garfinkel L, Stout AP. Histologic changes in bronchial tubes of cigarette-smoking dogs. Cancer 1967; 20: 2055-2066.

53. Park SS, Kikkawa Y, Goldring IP, et al. An animal model of cigarette smoking in beagle dogs. Am Rev Respir Dis 1977; 115: 971-979.

54. Wanner A, Hirsch JA, Greeneltch DE. Tracheal mucous velocity in beagles after chronic exposure to cigarette smoke. Arch Environ Health 1973; 27: 370-371.

55. King M, Wight A, De Sanctis GT, et al. Mucus hypersecretion and viscoelasticity changes in cigarette-smoking dogs. Exp Lung Res 1989; 15: 375-389.
56. Angus E, Amyot R, Martin R. Morphological changes in beagle dogs following exposures to $\mathrm{SO}_{2}$. Clin Res 1976; 24: 689A.

57. Scanlon PD, Seltzer J, Ingram RH Jr, Reid L, Drazen JM. Chronic exposure to sulfur dioxide: physiologic and histologic evaluation of dogs exposed to 50 or $15 \mathrm{ppm}$. Am Rev Respir Dis 1987; 135: 831-839.

58. Bhaskar KR, Drazen JM, O'Sullivan DD, Scanlon PM, Reid LM. Transition from normal to hypersecretory bronchial mucus in a canine model of bronchitis: changes in yield and composition. Exp Lung Res 1988; 14: 101-120.

59. King M, Boileau R, Delaunois L, Martin RR. Alteration in tracheal mucus viscoelasticity with chronic sulfur dioxide exposure (Abstract). Am Rev Respir Dis 1980; 121(2): 243.

60. Rubin BK, Ramirez O, Zayas JG, Finegan B, King M. Respiratory mucus from asymptomatic smokers is better hydrated and more easily cleared by mucociliary action. Am Rev Respir Dis 1992; 145: 545-547.

61. Zayas JG, Man GCW, King M. Tracheal mucus rheology in patients undergoing diagnostic bronchoscopy: interrelations with smoking and cancer. Am Rev Respir Dis 1990; 141: 1107-1113.

62. Vastag E, Matthys H, Zsamboki G, Köhler D, Daikeler G. Mucociliary clearance in smokers. Eur J Respir Dis 1986; 68: 107-113.

63. King M, Viires N. Effect of methacholine chloride on rheology and transport of canine tracheal mucus. $J$ Appl Physiol: Respirat Environ Exercise Physiol 1979; 47: 26-31.

64. King M, El-Azab J, Phillips DM, Angus GE. Antigen challenge and canine tracheal mucus. Int Arch Allergy Appl Immunol 1985; 77: 337-342.

65. King M, Tomkiewicz RP, App EM, Dasgupta B, Boyd WA. Effects of human neutrophil elastase (HNE) and recombinant secretory leukocyte protease inhibitor (SLPI) on airway epithelial function in dogs in vivo. Am J Respir Crit Care Med 1995; 151: A529.

66. Allegra L, Abraham WM, Chapman GA, Wanner A. Duration of mucociliary dysfunction following antigen challenge. J Appl Physiol: Respirat Environ Exercise Physiol 1983; 55: 726-730.

67. Tomkiewicz RP, Albers GM, De Sanctis GT, Ramirez OE, King M, Rubin BK. Species differences in the physical and transport properties of airway secretions. Can J Physiol Pharmacol 1995; 73: 165-171. 